\title{
A INFÂNCIA, AS FLORES E O TRABALHO INFANTIL: OS ENTRELAÇOS DISCURSIVOS ENTRE CONCEIÇÃO EVARISTO E OLAVO BILAC
}

\author{
The childhood, the flowers and the child labor: discursive interventions between \\ Conceição Evaristo and Olavo Bilac
}

\section{Cristiane de Mesquita Alves}

https://orcid.org/0000-0002-1723-9611

\section{José Guilherme de Oliveira Castro}

(iD) https://orcid.org/0000-0003-3602-7734

Universidade da Amazônia, Programa de Pós-Graduação em Comunicação, Linguagens e Cultura, Belém, PA, Brasil.66060-902-ppgclc@unama.br

Resumo: O objetivo deste artigo é apresentar uma análise comparativa entre o conto Lumbiá, um dos contos do livro Olhos d'água (2015) da escritora, professora e ativista social da atualidade Conceição Evaristo com a crônica Prostituição Infantil, publicada originalmente em 1894, no jornal Gazeta de Notícias pelo autor carioca Olavo Bilac, com intuito de aproximar nas duas leituras literárias a temática recorrente: o trabalho infantil e como ele se manifesta no discurso literário de forma crítica e de denúncia social no decorrer do tecido narrativo dos dois textos. Para tanto, a análise se estruturou a partir de uma pesquisa bibliográfica, embasada na revisão de literatura dos textos literários em discussão, assim como nos aportes teóricos sobre a vida, a caracterização estética das obras dos autores, sua contextualização no panorama sócioliterário no cenário da Literatura engajada brasileira presente nos estudos de livros e revistas acadêmicas, os quais serviram de sustentação para a argumentação desse estudo comparado.

Palavras-chave: Infância. Trabalho infantil. Literatura Comparada.

Abstract: The purpose of this article is to present a comparative analysis between the short story Lumbiá, one of the tales of the book Olhos Água (2015) by the current writer, teacher and social activist Conceição Evaristo with the chronic Child Prostitution, originally published in 1894, in the newspaper Gazeta de Noticias by the carioca author Olavo Bilac, in order to bring the recurrent theme closer to both literary readings: child labor and how it manifests itself in the literary discourse critically and socially throughout the narrative fabric of the two texts. Therefore, the analysis was structured from a bibliographic research, based on the literature review of the literary texts under discussion, as well as on the theoretical contributions about life, the aesthetic characterization of the authors' works, their contextualization in the socioliterary panorama in the literature. scenario of Brazilian Engaged Literature present in the study

Esta obra está licenciada sob uma Creative Commons - Atribuição 4.0 
of books and academic journals, which served as the basis for the argument of this comparative study.

Keywords: Childhood. Child labor. Comparative literature.

\title{
Introdução
}

\begin{abstract}
Não sei que jornal, há algum tempo, noticiou que a polícia ia tomar sob a sua proteção as crianças que aí vivem, às dezenas, exploradas por meia dúzia de bandidos. Quando li a notícia, rejubilei. Porque, há longo tempo, desde que comecei a escrever, venho repisando este assunto, pedindo piedade para essas crianças e cadeia para esses patifes. (BILAC, 1996, p. 305).
\end{abstract}

Escrever sobre e para a infância é uma prática recorrente na Literatura. E, colocar a pena da galhofa à mão, no dizer machadiano (ASSIS, 2008), para denunciar os maus tratos às crianças, sobretudo, no que se refere ao trabalho infantil foi temática na Literatura do passado, e, embora esta infeliz prática seja antiga, ela se configura como um dos mais graves problemas sociais que não deixa de estar presente, também nas páginas da Literatura da chamada era pósmoderna.

Os primeiros relatos do trabalho infantil no Brasil datam da época da escravidão, que perdurou por quase quatro séculos no país. Os filhos de escravos acompanhavam seus pais nas mais diversas atividades em que se empregava mão de obra escrava e exerciam tarefas que exigiam esforços superiores as suas possibilidades físicas. "O início do processo de industrialização, no final do século XIX, não foi muito diferente de outros países no tocante ao trabalho infantill”. (KASSOUF, 2007, p. 324), e esta realidade se propaga de forma semelhante aos dias atuais.

Tal situação foi retratada por Olavo Bilac (1996) em sua crônica Prostituição Infantil, ao contar um breve encontro do narrador do relato com a pequena vendedora de flores na frente de um teatro, em busca de conseguir dinheiro para o sustento da família (formada por ela, pela mãe, pelo homem lá de casa - possivelmente não era seu pai, mas a agredia se ela não voltasse para casa com dinheiro).

Publicada em 14 de agosto de 1894, no jornal Gazeta de Notícias, e, mais tarde, reunida como um dos textos que compõe o livro Vossa Insolência de Olavo Bilac (1996), a crônica apresenta uma releitura de um retrato social de sua época. Olavo Bilac, assim como outros poetas e escritores desse período, era cronista, jornalista profissional e um analista político de uma sociedade brasileira do final do século XIX marcada pela "transformação do espaço público, do modo de vida e da mentalidade carioca, segundo padrões totalmente originais; e não havia que pudesse se opor a ela." (SEVCENKO, 2003, p. 43). A transformação dessa sociedade, apontada por Sevcenko (2003) como transcurso de metamorfose baseava-se na condenação de valores e de hábitos e de costumes ligados à sociedade tradicional; a negação dos elementos da cultura popular que pudesse deturpar a imagem civilizada da sociedade dominante, assim como uma política rigorosa de expulsão dos grupos populares da área central da cidade, isolando-os para as periferias, deixando o centro para o desfrute exclusivo das camadas aburguesadas. Nessa crônica faz uma denúncia por meio de uma crítica mordaz da 
situação de menores que são explorados por adultos. Dentre suas principais denúncias está a omissão das autoridades, como a polícia, que não combate ao abandono das crianças, nem pune os responsáveis pela exploração infantil.

Este retorno temático pode ser exemplificado no conto Lumbiá da escritora mineira Conceição Evaristo (2015), no que retrata a temática do trabalho infantil, corroborando a premissa de laço comparativo proposto por Pichois \& Rosseau (2011), os quais designam que os textos literários dialogam entre si, entre muitos vieses, como forma e temática, etc., e que os textos deixam espaços para outros serem preenchidos, retornados, relidos e comparados.

Isto posto, semelhante à menina da crônica de Olavo Bilac (1996), tem-se o menino do conto de Conceição (2015) ; menino pobre que vive perambulando pelas ruas da cidade, do mesmo jeito que a criança de Bilac (1996), vendendo flores, para o sustento de sua família (formada pela indicação no conto, da mãe e da irmã - também vendedora ambulante, e do colega Gunga que acompanha Lumbiá pelas ruas da cidade). Por uma leitura geral, tanto a menina da crônica, quanto o menino do conto sofrem as investidas da sociedade indisposta a ampará-los, e pré-disposta a explorá-los.

Diante dessa reflexão, organiza-se este estudo dividido em dois momentos, além da introdução. No primeiro: pautado na discussão do tema social apontado nas obras e como seus autores reagem frente a ele e no segundo, faz-se uma análise com mais precisão a comparação literária entre os textos elencados para este fim, seguida da conclusão e das referências.

\section{Cada um em seu tempo, mas, nas mesmas histórias}

Essa relação especial com o passado tem também outro aspecto. A contemporaneidade inscreve-se, de fato, no presente assinalando-o antes de tudo como arcaico, e só quem percebe no mais moderno e recente os índices e as assinaturas do arcaico pode dele ser contemporâneo. (AGAMBEN, 2015, p. 30).

Olavo Bilac (Rio de Janeiro, 1865-1918) foi "o mais antológico dos nossos poetas." (BOSI, 2006, p. 226). O rótulo de escritor parnasiano, eloquente, de uma imagem que cristalizou sua obra oscilando entre "o perfil acadêmico de um príncipe dos poetas fiel à estética parnasiana e a aura de poeta popular cantado nas ruas e aclamado nas festas." (LAJOLO, 2003, p. 9), equilibrou-se com a temática social abordada em outra face de sua obra presente, sobretudo, nas crônicas e nas novelas.

De acordo com Bosi (2006), esta particularidade da escrita de Bilac, deu-se na ocasião da Revolta da Armada em 1893, quando o "poeta refugiou-se em Minas, aí escrevendo Crônicas e Novelas.” (BOSI, 2006, p. 226). Nesses textos, por seus assuntos mais cotidianos, poder-se-ia perceber também uma temática mais diversificada da obra do autor, popularizada pelos temas que versou com mais assiduidade, como "a beleza física da mulher, os cenários, os movimentos épicos da história nacional, ajustavam bem a esse traço exterior e retórico do seu modo de ser artístico." (BOSI, 2006, p. 228), abrangendo seus temas a questões sociais, próximos aos dos outros escritores de seu tempo da segunda metade do século XIX, os quais primavam por uma Literatura mais engajada, mais crítica, de denúncias às mazelas sociais que assolavam a

Anu. Lit., Florianópolis, v. 24, n. 2, p. 59-70, 2019. ISSNe 2175-7917 
sociedade de seu tempo, como a prostituição infantil e todas as circunstâncias que levavam para sua existência, como a desestrutura familiar, a corrupção da polícia, o descaso do Estado e da sociedade que não se prontificavam em apontar soluções para esta miséria da condição social, responsável por destruir uma parte fundamental da vida do homem: a infância. $\mathrm{O}$ discurso literário engajado dessa forma presente na crônica " [...] constitui possivelmente a porção mais dúctil, o limite mais extremo do discurso, o espaço onde ele se expõe por inteiro, visando reproduzir-se, mas expondo-se igualmente à infiltração corrosiva da dúvida e da perplexidade" (SEVCENKO, 2003, p. 28).

Por este motivo, Olavo Bilac usava sua arte como arte - denúncia, pois a arte nos textos de Bilac funcionava como uma voz portadora de denúncia e críticas a uma sociedade de injustiças sociais, como a prostituição infantil. De acordo com Jorge (2007, p. 311) "a própria natureza, disse ele, não trabalha de improviso. [...] Segundo Bilac, ninguém pode conceber um poeta que não seja suscetível de padecimento. A indiferença à dor é um mito, até as pedras, talvez, não conseguem viver sem alma.”. Nesse ínterim, pode-se justificar o posicionamento de Bilac, principalmente com base na leitura do texto selecionado para esta análise Prostituição Infantil, ao autor e sua obra configurados ao papel social designado por Candido (2006) como um dos aspectos da estrutura da Literatura na sociedade. Para o crítico literário brasileiro, o autor deve assumir um papel nas categorias sociais, do específico ao criador de arte, e como define a sua posição na escala social, o "que envolve não apenas o artista individualmente, mas a formação de grupos de artistas [...] levados a indicar [...] o aparecimento individual do artista na sociedade como posição e papel configurados". (CANDIDO, 2006, p. 34). Essa discussão é evidenciada também por Sevcenko (2003), quando aponta a intervenção da ação dos intelectuais na postura de modificação do bem estar burguês da sociedade, seja por meio das crônicas, seja por meio de certas atitudes de vinculação do artista com a realidade social em que ele está inserido.

Desse ponto de vista, corrobora-se a ideia de que "os elementos individuais de cada artista adquirem significado social, na medida em que os sujeitos correspondem a necessidades coletivas" (ALVES, 2018, p. 43); por esse ângulo, ao denunciar a exploração sexual, ou quaisquer outras formas de exploração da mão de obra infantil, Olavo Bilac acaba por definir também seu papel de artista, não só como um dos poetas mais líricos da Literatura brasileira, mas também, como um dos mais engajados socialmente.

Semelhante à voz social de Olavo Bilac, encontra-se na atualidade uma escritora de tamanha voz feminina responsável por promover em seus textos a denúncia e a reflexão sociais: Conceição Evaristo (Belo Horizonte- Minas Gerais, 1946). Professora e autora de uma vasta obra poética e em prosa, uma das maiores expressões da Literatura brasileira pós-moderna, seduz seu leitor pela exaltação da memória - afetiva ou étnica -, abordando em suas narrativas e versos fatos pessoais ou históricos - sociais, bem como a religiosidade híbrida brasileira, objetivando se "inscrever textualmente a realidade social e cultural dos afrodescendentes. Essa voz se faz audível ao abordar os aspectos da vida cotidiana da mulher, com seus dilemas e angústias, diante de uma sociedade marcada pelos valores patriarcais." (DUARTE; LOPES, 
2018, p. 1).

Suas narrativas são permeadas por intensa dramaticidade, que realça a tensão de violência, medo e injustiças sociais vividas no cotidiano por suas personagens em suas diversas ficções. Seus textos são habitados em espaços urbanos, onde confrontam excluídos e/ou marginalizados sociais, "mas deixando nítida na mente do leitor qual a cor da pobreza brasileira. No entanto, a autora escapa das soluções fáceis, não glamouriza o morro, nem investe no realismo brutal que termina transformando a violência em mercadoria." (DUARTE; LOPES, 2018, p. 2).

Além disso, há um lirismo trágico aliado à denúncia social em seus contos (DUARTE; LOPES, 2018) responsável por se referir ao universo íntimo dos humilhados e ofendidos, os quais são apresentados em sua ficção como seres sensíveis, marcados não apenas pelos traumas da vida difícil da rotina turbulenta dos grandes centros citadinos, mas também por desejos, sonhos, esperanças, embora frustradas, de que a vida pode melhorar como ocorre com a personagem Lumbiá escolhida para estudo neste artigo.

$\mathrm{Na}$ obra de Conceição Evaristo também, tem-se como um dos temas a presença da violência representada como um paradoxo entre sentimento de ternura a um realismo cru, beirando à releitura de um Naturalismo da segunda metade do século XIX, caracterizado por tingir no Realismo "no romance e no conto, sempre que fizer personagens e enredos submeterem-se ao destino cego das leis naturais." (BOSI, 2006, p. 168), além de impactar o leitor, a escrita de Evaristo "revela o compromisso e a identificação da intelectual afrodescendente para com aqueles irmãos colocados à margem do desenvolvimento." (DUARTE; LOPES, 2018, p. 2-3), dialogando ao preceito de engajamento social literário proposto por Antonio Candido em sua discussão de Literatura e Sociedade (2006).

As personagens de Evaristo nesse conto em análise são deterministas, se estender a análise comportamental das mesmas às condições sociais como determinantes de suas ações, como: o meio social, a raça (em especial a questão do negro, tão trabalhada entre seus enredos e versos), somados ao contexto social em que a narrativa se constrói: um território de medo e de malandragem, astúcia /esperteza, se partir da observação de Lumbiá, que se virava como podia para vender as flores, para trazer dinheiro para casa.

Escritora, graduada em Letras pela UFRJ, trabalhou como professora da rede pública de ensino da capital fluminense. Mestre em Literatura Brasileira pela PUC do Rio de Janeiro e Doutora em Literatura Comparada na Universidade Federal Fluminense. Participante ativa dos movimentos de valorização da cultura negra no país, estreou na Literatura em 1990, quando passou a publicar seus contos e poemas na série Cadernos Negros; Evaristo vê o seu tempo e compreende o seu papel de artista engajada frente a ele, Conceição Evaristo assume a postura também de intelectual da contemporaneidade, e entende de forma crítica a exigência dos problemas sociais atuais e a sombra dos problemas que não ficaram no passado, "de sermos contemporâneos não exclusivamente do nosso século e do "agora", mas também das suas figuras nos textos e nos documentos do passado [...].” (AGAMBEN, 2015, p. 33), e compreendê-los para melhor viver o presente e ter perspectiva no futuro. 
Diante dessas breves considerações sobre o contexto de vida e de obra, com ênfase na caracterização das temáticas das obras desses dois autores de diferentes estéticas literárias, esta seção foi apresentada, a fim de demonstrar uma pequena contextualização em que as discussões desenvolvidas nesse estudo estão inseridas. Nessa acepção, este trabalho abordará na sequência uma análise comparativa no que concerne à temática apresentada nas duas obras elencadas.

\title{
Flores no meio do caminho, em um dia de trabalho das crianças
}

\author{
No meio do caminho tinha uma pedra \\ Tinha uma pedra no meio do caminho \\ Tinha uma pedra \\ No meio do caminho tinha uma pedra \\ Nunca me esquecerei desse acontecimento \\ $\mathrm{Na}$ vida de minhas retinas tão fatigadas \\ Nunca me esquecerei que no meio do caminho \\ Tinha uma pedra \\ Tinha uma pedra no meio do caminho \\ No meio do caminho tinha uma pedra \\ (ANDRADE, 2013, p. 36).
}

Do ponto de vista histórico dissertado por Cunha (2013), as crianças ocuparam um lugar secundário no pensamento sociológico desde a definição usual da categoria criança/ infância, de forma mais recorrente, a partir do século XIX. Elas, quando a sociedade dava alguma atenção, foram consideradas atores coadjuvantes, e, muitas vezes, como figurantes, nas análises das tramas sociais, pelo fato das análises sociológicas privilegiarem o universo empírico dos adultos para descrever as sociedades. "É como se as sociedades fossem compostas apenas por indivíduos adultos ou, ainda, é como se apenas os relatos desses indivíduos fossem sociologicamente relevantes para a compreensão das sociedades." (CUNHA, 2013, p. 84).

$\mathrm{Na}$ Literatura, apesar do tema infância estar associado, de forma predominante, ao panorama das histórias dos contos de fadas, ao mundo lúdico, a infância protagonizou muitas páginas no âmbito literário, bem como serviu de temática recorrente as reflexões das análises literárias. Nas letras brasileiras, as discussões acerca do infantil intensificaram-se a partir da época do Romantismo e, principalmente do Realismo que foi um movimento artístico e cultural que se desenvolveu na segunda metade do século XIX, e que teve como característica principal a abordagem de temas sociais e um tratamento objetivo da realidade do ser humano, e dentre estes, o trabalho infantil acabou sendo inserido.

O trabalho infantil foi uma prática social comum na História das sociedades, em especial, a da capitalista porque as crianças e mulheres, além de serem mais maleáveis, consideradas inferiores pela sociedade patriarcal, também custavam menos ao empresário capitalista.

Por volta de 1860 , enquanto um operário adulto custava entre 18 e 45 xelins por semana, três meninos de 13 anos de idade custavam entre seis e oito xelins. Tal vantagem era tão lucrativa que o empresário capitalista preferia usar o trabalho de mulheres e crianças ao invés das máquinas, pois acarretaria um aumento no preço da produção. (CUNHA, 2013, p. 85). 
Frente a esta realidade, mulheres e crianças eram desprovidas de direitos e exploradas como podiam. Tal situação, ainda que em uma realidade ficcional, é descrita na crônica de Bilac e no conto de Evaristo. Em ambas as narrativas têm-se crianças trabalhadoras e ambas têm como ofício: vender flores.

$\mathrm{Na}$ crônica, há a descrição do encontro do narrador com a pequena menina, trabalhadora infantil:

\begin{abstract}
Anteontem, por horas mortas, [***] que me encheu de mágoa e de nojo, de indignação e de angústia. Saía de um teatro. [***] rua central da cidade, deserta há essa hora avançada da noite, vi sentada uma menina, a uma soleira de porta. Dormia. Ao lado, a sua cesta de flores murchas estava atirada sobre a calçada. Despertei-a.

A pobrezinha levantou-se, com um grito. Teria oito anos, quando muito. Louros e despenteados, emolduravam os seus cabelos um rosto desfeito, amarrotado de sono e de choro. E dentro do miserável vestidinho de chita, todo o seu corpo tremia como numa convulsão, nervosamente. Quando viu que não the queria fazer mal, o seu ar de medo mudou-se logo num ar de súplica. Pediu-me dez tostões, chorando. (BILAC, 1996, p. 306).
\end{abstract}

Pela caracterização física de maus tratos à criança em relação à aparência, percebe-se o descaso dos responsáveis, assim como da conjuntura social em cena, por ela. Pela a hora e pelas condições da menina, pressupõe-se que ela poderia estar ali por mais tempo, e não ter conseguido vender seu produto, já que as flores estavam murchas. Mas, pelo medo da recriminação e espancamento da mãe ou do homem que morava com elas, a pequena acabou pedindo dinheiro ao narrador, para se livrar da surra.

Já no conto de Evaristo (2015), existe outra criança, agora menino, também vendedor de flores:

Lumbiá trocou rapidamente a lata de amendoim pela caixa de chicletes com a irmã Beba. Fazia um bom tempo que estava andando e não havia conseguido vender nada. Quem sabe teria mais sorte se oferecesse chicletes? - Pensou. Se não desse certo também, procuraria o colega Gunga. Juntos poderiam vender flores. A mãe não gostava dessa espécie de mercadoria. (EVARISTO, 2015, p. 81).

Assim como a menina da crônica de Bilac, Lumbiá também tinha dificuldades para vender o seu produto que segundo a mãe não era um bom produto, porque flores murchavam, que chicletes ou amendoim durariam mais. Porém, o menino gostava de vender flores e, também tinha seus artifícios para vender seu produto ou ganhar alguns trocados por esperteza ou por malícia. Esses ardis da infância são traços semelhantes que se encontram nas duas leituras. Tanto o menino de Evaristo (2015), quanto a menina de Bilac (1996), por mais inexperientes que possam parecer em uma leitura rápida e despercebida, são muito espertos. Driblam os desafios da rua, encaram o medo da violência sexual e urbana com uma maestria, que vão além do território comportamental da infância, como suas vivências. Isso pode ser observado nas passagens: 
E a sua meia-língua infantil, espanholada, disse-me cousas que ainda agora me doem dentro do coração.

Perdera toda a féria. Só conseguira obter, ao cabo de toda uma tarde de caminhadas e de pena, esses dez tostões - perdidos ou furtados. E pelos seus olhos molhados passava o terror das bordoadas que a esperavam em casa...

"Mas é teu pai quem te esbordoa?"

"E um homem que mora lá em casa..."

Dei-lhe os dez tostões, sem poder falar.

Ela, já alegre, com um sorriso divino que lhe iluminava a face úmida, pediu-me mais duzentos reis - para si, esses, para doces.

Guardou a nota na cesta, e meteu a mesada na meia, depressa, para a esconder... (BILAC, 1996, p. 306-307).

Pela ação da menina, constata-se que o local de trabalho, a rua é encarada como um grande palco da vida, em que é preciso encenar para viver e para se proteger, além de também aproveitar o que resta da infância: ela esconde uma parte do dinheiro para comprar doces. Igual atitude atrevida e infantil se verifica no comportamento de Lumbiá:

Lumbiá tinha ainda outros truques. Sabia chorar, quando queria. Escolhia uma mesa qualquer, sentava, abaixava a cabeça e se banhava em lágrimas. Sempre começava chorando por safadeza, mas em meio às lágrimas ensaiadas, o choro real, profundo, magoado se confundia. Nas histórias que inventava nos momentos de choro para comover as pessoas, tinha sempre uma dissimulada verdade, algo semelhante tinha acontecido com ele ou com Gunga, seu amigo. Safanões da mãe, mercadoria encalhada, dinheiro perdido ou tomado por algum menino maior... $\mathrm{E}$ aos poucos, em meio às verdades-mentiras que tinha inventado, Lumbiá ia se descobrindo realmente triste, profundamente magoado, atormentado em peito-coração menino. (EVARISTO, 2015, p. 83).

Da mesma maneira que a menina de Bilac (1996), que chorou para ganhar dinheiro, quando não conseguiu vender as flores, Lumbiá também fez, com um misto de safadeza e teatro, até com mais astúcias que a pequena de oito anos da crônica de Bilac (1996). Ambos com essas ações podem ser vistos como uma criança sob situação de privação e maus tratos tendo que sobreviver em sociedade que não os acolheu de uma forma mais justa.

Ademais à guisa de análises comparativas entre essas duas tessituras, consta pontuar que em meio a muitos problemas sociais enfrentados e propícios a passar na vida, vagando nas ruas, por essas duas crianças, como: trabalho infantil, violência física, sexual, fome, preconceito racial etc., ainda existe um espaço destinado à infância: a menina guarda dinheiro para doces e o menino fica fascinado pelas imagens do natal; ele deixa de vender algumas flores para enfeitar o Deus-menino, e o Rei Baltasar, imagens expostas em uma das lojas da cidade em que ele passava em frente, quando saia às ruas para vender flores. A rua ainda assim é vista como um espaço destinado à infância.

Outro aspecto a se observar nessa leitura interpretativa das duas obras é a metáfora das flores escolhidas pelos autores. Esse elemento simboliza a beleza, a inocência, a delicadeza, o vigor e a vida - a infância. Por outro lado, representa o descolorido, o medo de machucar, o murchar como se estivesse aos poucos se diluindo da vida e da beleza, direcionando-se à morte. Nessa perspectiva, uma das análises que se pode atribuir à presença dessas flores, não só como objeto de venda, o símbolo do trabalho infantil nos dois textos, mas também o fim da própria 
infância, da própria existência efêmera das duas personagens, isto é, as flores morrem breves como a infância. Triste realidade está presente no final da crônica, em que Olavo Bilac (1996) ressoa e prediz um futuro trágico e doloroso para sua menina:

Demais, que custa abrir um inquérito para conseguir saber que grau de parentesco existe entre as crianças vendedoras de flores e os que as exploram? Eu, por mim, posso afirmar a quem de direito que, em cada grupo de dez crianças dessas, interrogadas por mim, duas apenas me têm dito que conhecem pai ou mãe...

Enfim, todos nós temos mais que fazer. E talvez a sorte melhor que se possa desejar hoje em dia a uma criança pobre - seja uma boa morte, uma dessas generosas mortes providenciais, que valem mais que todas as esmolas, todas as bênçãos, todos os augúrios felizes e... toda a comiseração dos cronistas. (BILAC, 1996, p. 308-309).

Esses augúrios, prenúncios de morte da infância são escutados pelo menino de Evaristo (2015), que acaba por morrer, sendo metaforicamente comparado a mais uma flor que murchou.

O dia caminhava para seis da tarde. O menino aguardava ali desde as nove da manhã. Em sua viagem costumeira, do subúrbio para o centro da cidade, se distanciou de Gunga e da irmã. Tinha flores nas mãos, rosas amarelas. Havia combinado com o amigo que venderiam flores, mas aquelas ele daria para o Menino Jesus e também poria algumas nas mãos do Rei Baltasar. Fazia frio, muito frio, era um dia chuvoso. Tinha a roupa colada sobre o corpo frágil a tremer de febre. A loja já estava para fechar. As vendas tinham cessado desde o dia anterior. Casarão Iluminado abrira somente para visitação pública ao presépio. Precisava chegar até lá. Como? Já tinha feito várias tentativas vãs, sendo expulso pelos seguranças. Ia arriscar sempre. Tinha de ir. Em dado momento aproximou devagar. Ninguém na porta. Mordeu os lábios, pisou leve e, apressado entrou. Entrou e viu.

Lá estava o Deus-menino de braços abertos. Nu, pobre, vazio e friorento como ele. Nem as luzes da loja, nem as falsas estrelas conseguiam esconder a pobreza e a solidão de Jesus Cristinho. Lumbiá olhava. De braços abertos o Deus-menino pedia por ele. Erê queria sair dali. Estava nu, sentia frio. Lumbiá tocou na imagem, à sua semelhança. Deus-menino, Deus-menino! Tomou-a rapidamente nos braços. Chorava e ria. Era seu. Saiu da loja levando o Deusmenino. O segurança voltou. Tentou agarrar Lumbiá. O menino escorregou ágil, pulando na rua.

O sinal! O carro! Lumbiá! Pivete! Criança! Êre, Jesus-menino!Amassados, massacrados, quebrados! Deus-menino, Lumbiá morreu! (EVARISTO, 2015, p. 85-86).

Logo, diante dessa breve análise o que se compreende é que a infância é um momento tão volátil e tão permeado de insignificâncias sociais, que essas duas crianças acabam por se tornar heroínas de suas próprias histórias, ao tentarem resistir a toda condição de mal estar na sociedade em que estão inseridas. Elas criam e recriam a vida, onde não thes foram dadas oportunidades, e para elas, o maior desafio, a maior resistência dentro desse sistema, não é só o trabalho que lhe furta o tempo da infância, mas furtar o tempo para elas poderem ser crianças.

\section{Conclusão}

Depois dessa simples leitura interpretativa da crônica de Olavo Bilac (1996) e do conto de Conceição Evaristo (2015), chega-se a algumas considerações conclusivas, como a de que o

Anu. Lit., Florianópolis, v. 24, n. 2, p. 59-70, 2019. ISSNe 2175-7917 
tema comum abordado nos dois textos serviu para a análise comparativa das obras, em tempos históricos e literários diferentes, não obstante, trazem à discussão a reflexão e a denúncia social que se alastrou e se faz presente na sociedade brasileira, pelo olhar crítico dos autores.

A criticidade como tom das vozes artísticas de Bilac e de Evaristo fez/ faz com que seus textos tematizem a Literatura como porta voz da denúncia, na qual tem o seu enunciador, ou seja, o autor como um instrumento social que questiona ações sociais que não chegam a todos os participantes dessa sociedade.

Isso pode ser verificado no decorrer da análise interpretativa dessa pesquisa, ao citar o trabalho infantil, como assunto nas duas narrativas, empregado pelos autores de forma a descrever como se processa o trabalho das crianças em uma sociedade capitalista que não enxerga elas como crianças, não se preocupa em velar por elas ou em protegê-las. Elas são tratadas como produtos, do mesmo modo que suas flores, que murchadas, podem ser substituídas por outras.

A efemeridade da infância retratada nos dois textos chama a atenção do leitor, bem como o caráter pessimista no que se refere ao futuro da mesma. Em Bilac (1996), ocorre o presságio de um futuro vazio ou sofrido, enquanto que em Evaristo (2015) há a morte efetiva da criança que nem teve a oportunidade de seguir este caminho de augúrios indicado na crônica de Bilac.

Logo, o que se nota na leitura de Prostituição Infantil e de Lumbiá é que o trabalho infantil coincide com a morte ou o caminho que leva à morte da infância, e não importa a época em que a Literatura anuncie essa tragédia, mesmo que velada ou implícita pelas metáforas literárias, é preciso que um escritor consciente de seu lugar de fala, denuncie. Olavo Bilac denunciou no século XIX, Conceição Evaristo denuncia no presente.

\section{Referências}

AGAMBEN, Giorgio. O que é contemporâneo? In: AGAMBEN, Giorgio. Nudez. Tradução de Davi Pessoa. Belo Horizonte: Autêntica Editora, 2015.

ALVES, Cristiane de Mesquita. Fatos da história na memória da escrita hatouniana. In: Marcos dos Reis Batista. (Org.). Caminhos nas letras: abordagens nos estudos da linguagem 2. ed. Porto Alegre- RS: Editora Fi, 2018. 2 v., p. 43-58.

ANDRADE, Carlos Drummond de. Alguma poesia. São Paulo: Companhia das Letras, 2013.

ASSIS, Machado de. Memórias Póstumas de Brás Cubas. In: ASSIS, Machado de. Obras Completas. 2. ed. Rio de Janeiro: Nova Aguilar, 2008. 1 v., p. 623-758.

BILAC, Olavo. Vossa Insolência: crônicas. Organização de Antônio Dimas. São Paulo: Companhia das Letras, 1996.

BOSI, Alfredo. História Concisa da Literatura Brasileira. 43. ed. São Paulo: Cultrix, 2006.

CANDIDO, Antonio. Literatura e Sociedade. 9. ed. Rio de Janeiro: Ouro sobre Azul, 2006.

CUNHA, Luis de Lima e. Os clássicos da "literatura" sociológica infantil: as crianças e a infância de acordo com Marx, Weber, Durkheim e Mauss. Plural, São Paulo, v. 20. n. 1, p. 83- 
98,

jun.

2013.

Disponível

em:

https://www.revistas.usp.br/plural/article/download/74416/78040. Acesso em 29/03/2019.

DUARTE, Eduardo de Assis; LOPES, Elisângela. Conceição Evaristo: literatura e identidade Crítica. Literafro, Belo Horizonte, 16 dez. 2018. Disponível em: www.letras.ufmg.br/literafro. Acesso em: 29/03/2019.

EVARISTO, Conceição. Olhos d'água. Rio de Janeiro: Pallas: Fundação Biblioteca Nacional, 2015.

JORGE, Fernando. Vida e obra de Olavo Bilac. Introdução de Menotti Del Picchia. 5. ed. São Paulo: Novo Século Editora, 2007.

KASSOUF, Ana Lucia. O que conhecemos sobre o trabalho infantil. Rev. Nova Economia, Belo Horizonte, v. 17, n. 2, p. 323-350, mai./ago. 2007. Disponível em: http://www.scielo.br/pdf/neco/v17n2/v17n2a05.pdf. Acesso em 29/03/2019.

LAJOLO, Marisa. Melhores Poemas de Olavo Bilac. In: BILAC, Olavo. Melhores Poemas de Olavo Bilac. 4. ed. São Paulo: Global, 2003.

PICHOIS, Claude; ROUSSEAU, André M. Para uma Definição de Literatura Comparada. Trad. de Monique Balbuena. In: CARVALHAL, Tania Franco; COUTINHO, Eduardo de Faria (Org). Literatura Comparada. Textos Fundadores. 2. ed. São Paulo: Rocco, 2011, p. 230-233.

SEVCENKO, Nicolau. Literatura como Missão: tensões sociais e criação cultural na Primeira República. 2. ed. São Paulo: Companhia das Letras, 2003.

\section{NOTAS DE AUTORIA}

Cristiane de Mesquita Alves (cris.mesquita28@hotmail.com) é mestra e Doutoranda em Comunicação, Linguagens e Cultura (PPGCLC - UNAMA). Bolsista Prosup/CAPES. Integrante do Grupo de Pesquisa Interfaces do Texto Amazônico. (GITA). Professora de Literatura e de Atividades Práticas de Docência da Universidade do Estado do Pará (UEPA).

José Guilherme de Oliveira Castro (zevone@superig.com.br) é doutor em Letras (PUC-RG). Professor e Psicólogo. Titular do Programa de Pós-Graduação em Comunicação, Linguagens de Cultura Mestrado e Doutorado (PPGCLC) da Universidade da Amazônia. Líder do Grupo de Pesquisa Interfaces do Texto Amazônico. (GITA). Atua pesquisando os seguintes temas: narrativa, conto fantástico, sociedade, imaginário amazônico e lirismo.

\section{Como citar esse artigo de acordo com as normas da revista}

ALVES, Cristiane de Mesquita; CASTRO, José Guilherme de Oliveira. A infância, as flores e o trabalho infantil: os entrelaços discursivos entre Conceição Evaristo e Olavo Bilac. Anuário de Literatura, Florianópolis, v. 24, n. 2, p. 59-70, 2019.

\section{Contribuição de autoria}

Cristiane de Mesquita Alves: Coletou os dados, analisou, elaborou o manuscrito a partir da orientação do orientador. Escreveu o manuscrito e apresentou os resultados das discussões. Também refez uma parte do trabalho orientada/exigida pelos pareceristas. 
José Guilherme de Oliveira Castro: Orientou o trabalho, assim como indicou os passos de construção (desenvolvimento do artigo).

\section{Financiamento}

Programa de Suporte à Pós-Graduação de Instituições de Ensino Particulares (Prosup); O presente trabalho foi realizado com o apoio da Coordenação de Aperfeiçoamento de Pessoal de Nível Superior - Brasil (CAPES) - Código de Financiamento 001. Portaria No 206, de 04 de Setembro de 2018.

\section{Consentimento de uso de imagem}

Não se aplica.

\section{Aprovação de comitê de ética em pesquisa}

Não se aplica.

\section{Licença de uso}

Este artigo está licenciado sob a Licença Creative Commons CC-BY. Com essa licença você pode compartilhar, adaptar, criar para qualquer fim, desde que atribua a autoria da obra.

\section{Histórico}

Recebido em: 31/03/2019

Revisões requeridas em: 04/09/2019

Aprovado em: 01/10/2019

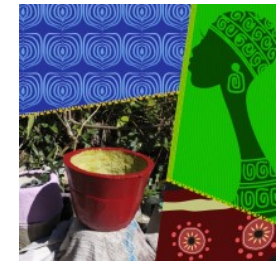

